\title{
Robotic pancreatic surgery is no substitute for experience and clinical judgment: an initial experience and literature review
}

\author{
Michael Wayne*, Justin Steele, Mazen Iskandar and Avram Cooperman
}

\begin{abstract}
Robotic pancreatic surgery offers technical advantages, and has been applied across many surgical specialties. We report an initial experience of 12 distal pancreatic resections for benign tumors from an established pancreatic center with previous general and biliary laparoscopic experience. Of a total of 12 patients, 7 were women; the mean age was 55.5 years, and the lesions included 8 distal intraductal papillary mucinous tumors, 1 insulinoma and in 3 a non-functioning neuroendocrine tumor. All operations were performed in between 90 and 180 minutes, and blood loss and hospital stay were minimal.
\end{abstract}

\section{Review Introduction}

The application and popularity of robotic surgery increase annually [1]. Robotics offer several advantages including three-dimensional visualization, enhanced dexterity through articulated instruments, higher magnification of the surgery site, and 'arms' that provide fixed traction and exposure [1-3]. Its adaptation in pancreatic surgery has lagged for technical, philosophical and economic reasons. We are an established hepatobiliary and pancreatic center, experienced in open pancreatic, and open and laparoscopic biliary surgery, but not robotic or laparoscopic pancreatic surgery. We report our first 12 robotic pancreatic resections, and review the relevant literature.

\section{Methods}

Between 14 November 2011 and 9 August 2012, 12 patients underwent pancreatic robotic surgery, using the DaVinci Surgical System (Intuitive Surgical Inc, 1266 Kifer Rd, Sunnyvale Calif 94066). The patients were seven women and five men. Ages ranged from 33 to 78 years, with a mean of 55.5 years and a median of 57 years. The indications for surgery were a distal intraductal papillary mucinous neoplasm (IPMN) in eight patients, an insulinoma in one patient and non-functioning neuroendocrine tumor (NET) in three patients (Table 1). The

\footnotetext{
* Correspondence: waynedocny@yahoo.com
}

The Pancreas and Biliary Center, New York, USA operations included one central pancreatectomy (CP), ten distal pancreatectomies without splenectomy (DP), and one distal pancreatectomy with splenectomy $(\mathrm{DP}+\mathrm{S})$.

\section{Results}

Operative times ranged from 1 hour and 30 minutes to 3 hours with a median of 2 hours and 50 minutes and a mean of 2 hours and 22 minutes. Blood loss was $100 \mathrm{~cm}^{3}$ or less in ten patients, $150 \mathrm{ml}$ in one patient and $350 \mathrm{ml}$ in another. The length of stay was 3 days in two patients, 4 days in nine patients, and 5 days in one patient. There were no fistulas or significant complications (Table 2).

\section{Discussion}

In 2003, Giulianotti et al. reported a series of robotic abdominal operations including the first pancreatic resection [4], and Melvin et al. reported a robotic excision of a neuroendocrine tumor [5]. While robotic operations have tripled between 2007 and 2010, there have been few reports of robotic pancreatic surgery [1,6]. Until recently most pancreatic surgery was performed for pancreatic adenocarcinoma, and most often required a Whipple operation, which can be intricate, lengthy and with significant morbidity $[7,8]$. Most distal pancreatic adenocarcinomas are large, rarely resectable or curable [7]. Why add robotics, time, cost and difficulty to an already grim situation?

The worldwide increase in body imaging has detected smaller, asymptomatic, and incidental pancreatic lesions $[9,10]$. These include cystic and neuroendocrine tumors, 
Table 1 Patient characteristics in present series $(n=12)$

\begin{tabular}{lc}
\hline Category & No. \\
\hline Gender, female:male & $7: 5$ \\
Age in years, mean (range) & 55.5 (33 to 78) \\
Indications: & 8 \\
Intraductal papillary mucinous neoplasm & 3 \\
Neuroendocrine tumor & 1 \\
Insulinoma & \\
Operation performed: & 10 \\
Distal pancreatectomy & 1 \\
Distal pancreatectomy with splenectomy & 1 \\
Central pancreatectomy & \\
\hline
\end{tabular}

which have a far better prognosis than adenocarcinoma $[9,10]$. When surgery is indicated, the small size and absent vascular involvement favor laparoscopy or robotics. Most robotic pancreatic procedures (60\% to $70 \%$ ) are performed for benign lesions less than $3 \mathrm{~cm}$, reflecting selection bias and sound judgment $[2,3,11,12]$.

We were late to adopt robotic pancreatic surgery since open distal resections took less than $1 \mathrm{~h}$ and pancreaticoduodenal resections $2.5 \mathrm{~h}$, both performed with minimal blood loss $\left(<150 \mathrm{~cm}^{3}\right)$, short hospital stay (5 to 8 days) and few pancreatic fistulas (0\% to 6\%) [13,14]. We reconsidered, as patients inquired and requested robotics. Our first robotic resection took 3 hours, and the most recent 1 hour and 30 minutes. The mean time was 2 hours and 22 minutes. There are four published case series of robotic distal pancreatectomy. The number of patients and operative times for each were: 17 patients (4 hours and 58 minutes) [2], 20 patients ( 5 hours and 40 minutes)

Table 2 Results for present series

\begin{tabular}{ll}
\hline Category & Finding \\
\hline Gender, female:male & $7: 5$ \\
$\begin{array}{l}\text { Operative time in hours (h) and } \\
\text { minutes (m), mean (range) }\end{array}$ & $2 \mathrm{~h}$ and $22 \mathrm{~m}$ \\
Estimated blood loss: & $(1 \mathrm{~h}$ and $30 \mathrm{~m}$ to $3 \mathrm{~h})$ \\
$<100 \mathrm{ml}$ & 10 \\
100 to $200 \mathrm{ml}$ & 1 \\
300 to $350 \mathrm{ml}$ & 1 \\
Length of stay: & \\
3 days & 2 \\
4 days & 9 \\
5 days & 1 \\
Complications: & \\
Mortality & 0 \\
Pancreatic fistula & 0 \\
Others & 0 \\
\hline
\end{tabular}

Table 3 Reported outcomes of robotic distal pancreatectomies

\begin{tabular}{lccccc}
\hline Reference & $\begin{array}{c}\text { Patients, } \\
\mathbf{n}\end{array}$ & $\begin{array}{c}\text { Operative } \\
\text { time, hours (h) } \\
\text { and minutes } \\
(\mathbf{m})\end{array}$ & $\begin{array}{c}\text { Length of } \\
\text { stay, days }\end{array}$ & $\begin{array}{c}\text { Blood } \\
\text { loss, } \mathbf{~ m l ~}\end{array}$ & Fistulas \\
\hline Waters et al. [2] & 17 & $4 \mathrm{~h}$ and $58 \mathrm{~m}$ & 4 & 279 & 0 \\
Kang et al. [3] & 20 & $4 \mathrm{~h}$ and $58 \mathrm{~m}$ & 7.18 & 372 & - \\
$\begin{array}{l}\text { Daoudi } \\
\text { et al. [11] }\end{array}$ & 30 & $4 \mathrm{~h}$ and $53 \mathrm{~m}$ & 6.1 & 212 & 14 \\
$\begin{array}{l}\text { Giulianotti } \\
\text { et al. [12] }\end{array}$ & 46 & $5 \mathrm{~h}$ and $31 \mathrm{~m}$ & 9.3 & 323 & 9 \\
\hline
\end{tabular}

[3], 30 patients (4 hours and 5 minutes) [11] and 46 patients (5 hours and 31 minutes) [12] (Table 3).

Our series included one central resection. Three reports of robotic central resection include three, five, and nine patients with mean operating times from 5 hours and 20 minutes to 8 hours 0 " $[1,14,15]$. The fistula rates were one in three [15], one in five [16] and seven in nine [1] and the hospital stay ranged from 9 to 28 days. The operating time was influenced by the distal pancreatic anastomosis, that is, pancreaticogastrostomy, or pancreaticojejunostomy. We favor closure rather than anastomoses of the distal duct in central resections, as it shortens hospital stay, and operating time, minimizes fistula rates and does not increase exocrine insufficiency [17].

The robotic pancreatic studies indicate satisfaction with robotics, fewer conversions to open surgery and greater splenic preservation as compared to laparoscopy $[1,3]$. A large laparoscopic pancreatic experience generally precedes pancreatic robotic surgery. Despite this experience, most reported robotic operations took at least $5 \mathrm{~h}$, double our initial experience. Our lack of laparoscopic pancreatic experience was balanced by the benefits of a large open experience, which provided intimate familiarity with pancreatic anatomy, and insights into case selection, and intraoperative decision making.

The cost of robotic surgery is a valid concern. Waters et al. compared the cost of robotic distal pancreatectomy (R) to open $(\mathrm{O})$ and laparoscopic distal pancreatectomy $(\mathrm{L})$ in 77 cases [2]. The mean operating times and hospital stay were for $\mathrm{O}$ ( 3 hours and 42 minutes; 8 days), for L ( 4 hours and 5 minutes; 6 days), and for R (4 hours and 58 minutes; 4 days). The total cost for $\mathrm{R}, \mathrm{O}$ and $\mathrm{L}$ were US $\$ 10,588$, US $\$ 12,986$, and US $\$ 16,059$. The higher operative cost for robotics was offset by a shorter stay for robotic procedures.

Our operating room charges were slightly higher for robotics (R) compared to open surgery (O) US $\$ 2,180.48$ versus US $\$ 1,750.09$ but were offset by a shorter hospital stay, 3.9 days $(\mathrm{R})$ versus $6.5(\mathrm{O})$. Kang et al. noted in Korea that costs were 2.5 times higher for robotic versus laparoscopic distal pancreatic resections, not offset by hospital costs. [3]. 
Robotic distal pancreatectomy is safe, and its inherent advantages benefit patients and facilitate surgery in appropriately selected cases.

\section{Conclusions}

In all, 12 patients with benign pancreatic tumors underwent robotic pancreatic distal resection (11), and central resection (1). Operative times ranged from 1 hour and $30 \mathrm{mi}-$ nutes to 3 hours, blood loss less than $100 \mathrm{~cm}^{3}$ in ten patients, $150 \mathrm{~cm}^{3}$ in one patient and $350 \mathrm{~cm}^{3}$ in another. Hospital stay was 3 to 4 days for 11 patients and 5 days for 1 patient. Careful selection of patients and a large pancreatic experience allow satisfactory outcomes after pancreatic resections and may equalize or outweigh minimally invasive experience.

\section{Competing interests}

The authors declare that they have no competing interests.

\section{Authors' contributions}

MW and JS provided the clinical data, followup on each patient and edited the manuscript; Ml gathered the literature, followed up with each patient and with AC wrote the manuscript. AC formated, wrote (withMl), and edited the manuscript. All authors declare they read and approve the manuscript.

Received: 6 November 2012 Accepted: 7 July 2013

Published: 18 July 2013

\section{References}

1. Winer J, Can MF, Bartlett DL, Zeh HJ, Zureikat AH: The current state of roboticassisted pancreatic surgery. Nat Rev Gastroenterol Hepatol 2012, 9:468-476.

2. Waters JA, Canal DF, Wiebke EA, Dumas RP, Beane JD, Aguilar-Saavedra JR, Ball CG, House MG, Zyromski NJ, Nakeeb A, Pitt HA, Lillemoe KD, Schmidt CM: Robotic distal pancreatectomy: cost effective? Surg 2010, 148:814-823.

3. Kang CM, Kim DH, Lee WJ, Chi HS: Conventional laparoscopic and robotassisted spleen-preserving pancreatectomy: does da Vinci have clinical advantages? Surg Endosc 2011, 25:2004-2009.

4. Giulianotti PC, Coratti A, Angelini M, Sbrana F, Cecconi S, Balestracci T, Caravaglios $\mathrm{G}$ : Robotics in general surgery: personal experience in a large community hospital. Arch Surg 2003, 138:777-784.

5. Melvin WS, Needleman BJ, Krause KR: Ellison ECRobotic resection of pancreatic neuroendocrine tumor. J Laparoendosc Adv Surg Tech A 2003, 13:33-36.

6. Barbash Gl, Glied SA: New technology and health care costs - the case of robot-assisted surgery. N Engl J Med 2010, 363:701-704.

7. Cooperman AM: Pancreatic cancer: the bigger picture. Surg Clin North Am 2001, 81:557-574.

8. Cooperman AM, Fader A, Cushin B, Golier F, Feld M, Kasmin F, Cohen S, Mahadevia P, Shah K: Surgery and cancer of the pancreas: will common sense become common practice? Hematol Oncol Clin North Am 2002, 16:81-94.

9. Tanaka S, Nakao M, loka T, Takakura R, Takano Y, Tsukuma H, Uehara H, Suzuki R, Fukuda J: Slight dilatation of the main pancreatic duct and presence of pancreatic cysts as predictive signs of pancreatic cancer: a prospective study. Radiol 2010, 254:965-972.

10. Sahani DV, Saokar A, Hahn PF, Brugge WR, Fernandez-Del CC: Pancreatic cysts 3 cm or smaller: how aggressive should treatment be? Radiol 2006, 238:912-919.

11. Daouadi M, Zureikat AH, Zenati MS, Choudry H, Tsung A, Bartlett DL, Hughes SJ, Lee KK, Moser AJ, Zeh HJ: Robot-assisted minimally invasive distal pancreatectomy is superior to the laparoscopic technique. Ann Surg 2013, 257:128-132.

12. Giulianotti PC, Sbrana F, Bianco FM, Elli EF, Shah G, Addeo P, Caravaglios G, Coratti A: Robot-assisted laparoscopic pancreatic surgery: single-surgeon experience. Surg Endosc 2010, 24:1646-1657.

13. Cooperman AM, Schwartz ET, Fader A, Golier F, Feld M: Safety, efficacy, and cost of pancreaticoduodenal resection in a specialized center based at a community hospital. Arch Surg 1997, 132:744-747.

14. Coopermann AM: Pancreaticoduodenal resection: pearls, perils, and pitfalls. Surg Clin North Am 2001, 81:579-593.
15. Giulianotti PC, Sbrana F, Bianco FM, Addeo P, Caravaglios G: Robot-assisted laparoscopic middle pancreatectomy. J Laparoendosc Adv Surg Tech A 2010, 20:135-139.

16. Kang CM, Kim DH, Lee WJ, Chi HS: Initial experiences using robot-assisted central pancreatectomy with pancreaticogastrostomy: a potential way to advanced laparoscopic pancreatectomy. Surg Endosc 2011, 25:1101-1106.

17. Wayne M, Neragi-Miandoab S, Kasmin F, Brown W, Pahuja A, Cooperman AM: Central pancreatectomy without anastomosis. World J Surg Oncol 2009, 7:67.

doi:10.1186/1477-7819-11-160

Cite this article as: Wayne et al:: Robotic pancreatic surgery is no substitute for experience and clinical judgment: an initial experience and literature review. World Journal of Surgical Oncology 2013 11:160.

\section{Submit your next manuscript to BioMed Central and take full advantage of:}

- Convenient online submission

- Thorough peer review

- No space constraints or color figure charges

- Immediate publication on acceptance

- Inclusion in PubMed, CAS, Scopus and Google Scholar

- Research which is freely available for redistribution 